\title{
Autologous PBMCs in GM-CSF
}

National Cancer Institute

\section{Source}

National Cancer Institute. Autologous PBMCs in GM-CSF. NCI Thesaurus. Code C120182.

Autologous peripheral blood mononuclear cells (PBMCS) that are suspended in a solution containing the immunostimulant granulocyte-macrophage colony stimulating factor (GM-CSF). 